\title{
Landscape Art in Chinese Buddhist Temples
}

\author{
Xuelan Yang \\ East China Jiaotong University, Nanchang 330013, China.
}

\begin{abstract}
Keywords: Cultural fusion, Chinese Buddhism, Temple landscape, Art culture.
\end{abstract}
\begin{abstract}
Temple is regarded as deference thirst place, and is also regarded as ingenuity truth place, which is the symbol of China's long history culture, and has played a huge role in condensed human beliefs. At present, it is growing fusion contradiction between the temple landscape art and cultural market in china, the temple architectural landscape development is undeserved, there is difficult to fuse to the Buddhism culture, human spiritual needs and modern landscape function, which will influence heritage and development of national cultural for Buddhism. The mood ladder of god without way and contact send is established, the essence of constant content of affection is analyzed, and the mechanism of Zen oblivious oneself state is explored for field of architecture. This project will put forward a complete set of modern design methods for retaining the essence and interest of the Chinese Buddhism temple landscape, which can provide theoretical and enabling technical support for improving the quality of Chinese Buddhism temple landscape art.
\end{abstract}

\section{Foreword}

Temple is a place that represents for reverence and formless, and it's a symbol of Chinese splendid culture, and it plays an important role in condensing human belief. Buddhism belief is reviving constantly, and the number of believers is increasing hugely, then relevant tourism is booming. All walks of life make a point of building Buddhist temples, and even take Buddhist temples building as culture brand to promote economic development, such as South mountain in San-ya, Spirit mountain in Wu-xi and some other large Buddhist landscapes. But there are some realistic problems when building Han Buddhist temples in China, such as larger building, chasing luxuriousness and grandeur, simply imitating ancient ways, lacking characteristic, stiff landscape and so on. It's an urgent problem that how to master the

microscopical development and detailed building skills of modern Buddhist landscape.

\section{Relevant Study}

At present, the direct study on the modernization of Buddhist temple landscape is not so much, there are mainly two kinds of relevant study.one kind studies Buddhist temple landscape from the outline angel, containing artistic conception, the feature of location, placement scheme, characteristic, landscape elements and so on. This kind of study is universal. Jin Hexian, Guan Xin studied molding the artistic conception of temple garden[1]. Wang Yuan summarized the features of Buddhist architecture by the theory of phenomenology of architecture[2]. Dai Jian proposed opinion about the placement of Buddhist temple[3]. Zhou Weiquan, the professor of Tsinghua University, regarded temple garden as a branch of Chinese classical gardens and narrated the formation and evolution of temple garden[4]. Zhao Guanghui system studied the environment types and the structure and placement of scenery of the garden[5]. Liu Taiping studied the space composition of traditional temple courtyard[6]. Another kind of study based on the landscape of regional temple garden, which are mainly located in Shanxi province, Sichuan province, Anhui province and so on, in these provinces Buddhism is prosperous. Shen Yu studied the space form of courtyard, the palace hall's space form and spatial organization mode in Shanxi's Buddhist architecture[7]. Mei Teng studied the feature of architectural placement and its evolution in Henan's Buddhist temple[8]. Above studies embodies academics attach importance to the architecture scenery of Buddhist temple, but it still lacks expert and quantitative study on the modernization of landscape in Buddhist temple. 
Buddhism mainly spread in Asian areas, such as India, Thailand, Burma, Japan and so on. These countries shares the same belief. But in different times and different cultural backgrounds, it formed different temple landscapes, which reflects Buddhist culture generated distinctive differences in different regions, customs, natural conceptions and then formed totally different landscape types. 'Shaping the environment from prehistory to the present day: the landscape of man' collaborated by Groggery and Sunan-Jellieoe[9], 'Essentials of Japanese Buddhist History' simplified by Japanese scholar Haruki, the USA[10], 'The Revival of Chinese Buddhism compiled by Holmes.Weiz, the USA and some other books detailed discussed Buddhist cultural backgrounds, life habits of Buddhist, the rapid development of temple, the historical development of temple and exchange of Buddhist culture in abroad. In the article 'Efficacious Surroundings:Temple Space and Buddhist Well-being' written by Michael-Swan, he took TianZhu Temple as his studying object and made intensive reasarch on religious faith, Buddhist discipline in Chinese Buddhist background, and made detailed contrast analysis about the landscape composition of Buddhist temple[11].

\section{Research Method}

\subsection{Object of Study}

This paper chooses landscape in temple architectures of Chinese Buddhism as the object of study and discusses, how can planning and design of Buddhist architecture adapt to the use by monks and the external condition, like the society, the era, the region and so on, with the modernization of Buddhism belief and its organization. And how can environment and atmospheres of 'a tranquil and peaceful Buddhist garden' be created, keeping the nature of Buddhism and in accordance with the conception of cultural inheritance and innovation and then an cultural landscape, which modern people are glad to accept, be created. This landscape must combine with the environmental landscape, to create an ideological level of integrate harmony. At the same time, it must own the function of 'serving the public'. It became a crucial research direction of the modern Buddhist architecture landscape, that the modules of modern landscape design through its rebuild, extension and relocation caters to the fancy of human beings and suits the development of modern tourism.

\subsection{Contents of Study}

The following is the main research aspects:

(1)cultural landscape of Chinese Buddhism based on the propagation approaches of the Buddhism: 1..Analyze Buddhist landscape in different regions, based on different Buddhist schools, which came into being during its propagation. And then draw a conclusion of different forms of manifestation between plants landscape and architectural landscape. 2. Analyze the constructive characteristics and structural forms of plants landscape in Buddhist architectures and probe into the theoretical basis of landscape in temple architectures of Chinese Buddhism, combining with propagation approaches of Buddhist culture and types of layout of Buddhist architecture.

(2)Construction of ideal condition of Zen ideology based on the 'five aggregates': 1.Study the Buddhist cultural landscape and the perception of human beings, and then interpret and analyze it from the view of 'five aggregates'. 2.Divide the whole garden into pro-area, district for supplying of articles for daily use and sightseeing district through district line. Consequently, an emotional ladder, which connects this mortal life with Sukhavati, is built. 3.Express the religious state of 'From restraining oneself emerges peace, from peace emerges wisdom' in the Zen-garden through the integrate plants community, corresponding relationships and construction by human beings.

(3)Modern Zen landscape based on the conception of 'vacancy': 1.Probe into the realm of comprehension of Zen ideology, emphasize self-enlightenment and call for abrupt realization, then Buddhist architectures for individual meditation are created. 3.Connect the Buddhist architecture with classic Chinese garden through 'doctrine' and 'zen ', study the designing principle and creation of ideal conditions of modern Buddhist garden landscape, express the Buddha by applying color, sound, fragrance, symbol, and texture specially provided for Buddhist, and deliver the essence of Buddhism.

\subsection{Research on the Problems Needed to Be Solved}

(1) create the garden environment and atmosphere of 'Buddhist environment', to retain the essence of Buddhism. 
At present, many young people choose to believe in foreign religion to fill up their inner emptiness. How to inherit Zen religious culture with ethnic characteristics ,to solve the lack of Zen landscape environment, and how to meet the the public needs, there are many difficulties and challenges in realistic environment. This is one of the key issues in this research, which needs to be studied deeply by researching, demonstrating, case analyzing, environmental researching, psychological researching and so on, in the modern design theory and construction technology, making the landscape of Chinese Buddhist temple have religious atmosphere of 'from the discipline to quiet heart, from the quiet heart to wisdom', so that believers can find a religious sense of belonging in the process of worship.

(2) Based on the needs of the public belief, building 'God is invisible but in all things' emotional ladder.

Buddhism is the sublimation of secular culture, because the modern society to maximize the pursuit of interests, so that religious beliefs don't have a pure desire, leading to the reduction of traditional religious beliefs devout. Therefore, when building the 'earthly $\rightarrow$ Pure Land' ladder in the modern Buddhist temple landscape, need to understand and analyze the public expectations on the current environment, beliefs and atmosphere deeply, to determine the theme of the Buddhist landscape atmosphere, so Zen culture can be shown and created maximization.

(3) 'To see a world in a wild flower, and a bodhi in a leaf.' religious and cultural connotation and psychological hints: Using Buddhist implication of plants and animals, to create a rich Zen culture, analysis of Buddhist cultural landscape connotation, meet the demands of the public beliefs through the psychological implication of Buddhism.

\section{Conclusion}

This article studies the landscape art of Chinese Temple, and through field investigation and data analysis, the following methods are put forward:

(1) Put forward the new concept based on the 'Buddhist net environment' under the Zen cultural landscape construction.

Domestic Buddhist temple landscape lacks territoriality, and Zen conception is weak, the temples have overload operation. The traditional Buddhist temple landscape can only show the Buddhist culture through the simple Buddha statues, and the combination of the concept of 'gods' and the natural landscape is less. The concept of Zen cultural landscape construction based on 'Buddhist net environment' is completely different. It combines 'Buddha to the landscape' as the 'Buddhist net environment' foundation with expression of 'up to the big things' to achieve Buddhism 'gods' in the landscape landscape, and create a Zen cultural landscape conforming to contemporary Buddhist beliefs effectively.

(2) propose the new method of using Buddhist temple architectural landscape to build 'earthly' $\rightarrow$ 'pure land' mood brewing ladder

Inheritance of the Buddhist landscape is the perfect combination of Buddhist beliefs and daily life, so that the public in the natural landscape, in the process of experiencing individual survival experience feel the 'Buddha to landscape' atmosphere. Buddhist temple architectural landscape in the expression of the Buddhist atmosphere occupies an unshakable position, through the Buddhist temple architecture and natural landscape integration of a unified process of interaction, building the 'earthly' $\rightarrow$ "pure land" mood brewing ladder, to achieve the abstract mystery and the daily behavior of the public life and the needs of the integration of unity, and truly reflecting the landscape of Buddhist atmosphere.

\section{References}

[1]. Li Yang. Discussing about the design of Buddhist temple landscape based on

[2]. Eco-design. Development Opment Guide to Building Materials[J]. 2016,14(3):157-158.

[3]. Xiaoli, Zhao Lei. Wu A simple analysis on how the artistic culture of Buddhist temple influence the public psychology. Art science and Technology[J]. 2014(3): 198-199. 
[4]. Zong Hua, Zhang Nan. Research progress on Chinese traditional temple garden. Journal of Anhui Agricultural Science[J]. 2013,41(7):3009-3011.

[5]. Lou Juan, LouFei. Buddhism, Boundless, naturalness, quiet:Simple analysis on the artistic conception of Fengxue temple in Henan. Ecological and Economy[J]. 2013(8):179-182.

[6]. Xie Xiaofei, Long Yuelin. Inheriting and using Chinese Buddhist culture in designing courtyard landscape[J]. Journal of Hunan Agricultural University (Natural

[7]. Science ). 2012,38(1):90-93.

[8]. Yan Hongxia. The environment and protection of Han Buddhist garden[J]. Ecological Economy. 2013,7:189-192.

[9]. Feng Changming, Yu Jing. Contradiction and adjustment in developing Lushan's Buddhist tourism[J]. China Business and Trade. 2011,12(C):138-139.

[10]. Xu Wenting, Lin Jianqun. Unscrambled Study on Chinese Buddhist Culture Landscape and Five Aggregates [J]. Journal of South China University of Technology (Social Science Edition) . 2013,15(2):98-102.

[11]. ] Huang Chunhua,Li Jing. Research on the Buddhist Architectural Space in the middle Ages in China [J]. HuaZhong Architecture. 2010(4):182-183.

[12]. Yin An, Shi Xuqian. Zen Thought and Cultural Connotation in the Chinese Scenery Botanical Garden Landscape [J]. Hundred School in Art. 2008(6):117-120.

[13]. Liu Songlai, Zhou Xingtai. Zen and the landscape of JiangXi Prose in the Song Dynasty [J]. WuHan University Journal (Humanity Sciences). 2012,65(4):105-110. 